\title{
EL SONIDO DE LA BATALLA EN BERTRAN DE BORN
}

\author{
J.E. Ruiz Doménec
}

E] hombre primitivo no suele analizar lo que ve; percibe cada fenómeno como una totalidad, es decir, como una forma ritmica indisoluble.

Marius Schneider

El 19 de julio de 1195 tuvo lugar la batalla de Alarcos: tenue derrota de las armas castellanas, último aullido de los almohades en la Península Ibérica. Cinco años antes, en el verano de 1190 según L.E. Kastner, o, simplemente, un año antes, en el verano de 1194 según István Frank, Bertran de Born, poeta y trovador, señor de Auteford en el Peirigord, había escrito un sirventés que, junto con otros, desarrolla en detalle la estricta circunstancia de la clase dominante en la última década del siglo XII ${ }^{1}$.

1 En el presente trabajo utilizaré la edición de Carl APPEL, Die Lieder Bertrans von Born, Halle/Saale, Max Niermeyer Verlag, 1932. La personalidad histórica de nuestro poeta ha sido trazada por Albert SHMming, Bertrand von Bom. Sein Leben und seine Werke, Túbingen, 1892. Reedición, Genève, Slatkine Reprints, 1975; R. DE BOYsSON, Études sur Bertrand de Borm, sa vie, ses oeuvres et son siêcle. Paris, 1902. Reedición, Genève, Slatkine, 1973; Stanislaw StronsK1, 
Estas poesías, analizadas desde la perspectiva que permite hoy la historia social, reflejan por un lado el profundo esfuerzo que los feudales desartollaron para comprender la naturaleza de los ideales caballerescos; $y$, por otro, el sentimiento dramático que tuvieron al constatar la decadencia de la virtíd aristocrática como norma vital, soberana, mundanal ${ }^{2}$. Esa rudeza quieta, que observamos en los

La légende amoureuse de Bertran de Born, Paris, 1914. Reedición, Genève, Slatkine, 1973, y Martin DE RIQUER, Los trovadores. Historia literaria y textos, Barcelona, 1975, vol. II, p. 679-689. De esta obra además tomaré las excelentes traducciones al castellano que acompañan al texto provenzal. El problema de la cronologia del sirventés que dedica al parecer a la batalla de Alarcos, puede verse en L.E. KaSTnER, eNores on the poems of Bertran de Borns, en The Modern Language Review, 1932, 1933, 1934, 1936 y 1937, y en M. DE RIQUER, op, cit., p. 734.

Yo no dudaría en considerar toda la experiencia poética de Bertran de Born plenamente inclusa en una problemática histórica, por lo que las discusiones por la precisión de la cronología de una poesia son fundamentales, y en modo alguno hechos secundarios. La historia social se asienta en un escrupuloso sentido de la cronología y en la precisión de la fuente que analiza. Pero hay siempre en los estudios sobre análisis social de la literatura una indecisión profunda que no logra distinguir la realidad de la ficción literaria. En este sentido el trabajo que ahora comienzo debe mucho a las precisiones a que llegué sobre la propia situacionalidad histórica (y consecuentemente destinacional) del poeta de Auteford, en J.E. RUiz DOMf́nEC, La aventura imposible de Bertran de Born. Génova, Saggi e Documentí, II, 1981. El segundo trabajo sobre el poeta Bertran puede considerarse casi en sentido literal como una segunda parte, por ampliación en el cuestionario y por profundización en una etapa ulterior del peregrinar social e imaginario de Bertran. Hecha esta observación se comprenderá fácilmente que algunos de los elementos que quedan aquí simplemente sugeridos son ampliamente analizados en el anterior trabajo.

2 No me cabe la menor duda que planteo aquí un problema extraordinaria. mente controvertido. De los finos análisis que ha llevado a cabo el profesor Karl BOSL sobre la estructura fundamental de la sociedad europea, caben subrayar aquellos que han tratado de precisar la posible existencia de un núcleo aristocrá. tico inicial (semejante por ejemplo al del mundo griego en su periodo arcaico) que incorpora todo un conjunto normativo, de valores, que se contempla con dificultad en las fuentes, pero que responsablemente parece existir. Ese conjunto axiológico de contenido aristocrático ha sido planteado como una teoría general por el propio Karl BOSL en un trabajo muy sugerente denominado Die aristokratische Struktur der mittelalterlichen Gesellschafts en Die Gesellschaft in der Geschichte des Mittelalters, Göttingen, 1966, p. 25-43, donde incluso habla del sentido de la virtus como la fuerza moral que inspira el contenido de la aristocra. cia. El trabajo de su discípulo Hatto KanFeIZ, Das Standesethos des Adels im 10. und 11. Jahrbundert, Diss. Phil. Würzburg, 1960, precisa esta teoría con un profundo análisis de los textos narrativos y de los relatos hagiográficos donde se pueden encontrar los valores que determinan la consistencia de una clase social. En esta misma línea debe consultarse el excelente trabajo de Wilhelm STORMER, 
versos de Bertran, hemos de entenderla como la simple presentación de una actitud de rechazo del universo estético feudal y de la esencia de sus valores incuestionables, reafirmándose conscientemente como una alternativa a la crisis de significación de la sociedad feudal.

Para Bertran la única posibilidad de realización mundanal se halla en la aceptación de lo-socialmente-nuevo a finales del siglo XII: la corte y la aventura caballeresca. Sólo desde este punto de vista es posible comprender los objetivos y la naturaleza de una nueva concepción de la belleza que el poeta exige para conjurar las sombras blancas que habían coordinado la organización social en la época feudal ${ }^{3}$.

La poesía de Bertran no sólo busca superar los vicios sociales de finales del siglo XII, instaurando un lenguaje grave para subrayar con exactitud el permanente estado de alienación de la clase dominante, sino que también ansía encontrar una nueva explicación del sentido de la guerra y la agresión. De hecho, la ruina moral que afectó profundamente a la nobleza en las tres últimas décadas del siglo XII alcanza su máxima extensión en la naturaleza de la acción militar. Sin embargo, para nuestro poeta, todo noble es, a pesar de cualquiera de sus actos, noble; siendo la fortaleza que inspira sus actos guerreros el único elemento que permite hablar del sentido del honor. Así, en cierto sentido, lograr legitimizar la turbulencia mediante el ideal de aventura, inscribiendo los máximos cuidados poéticos en determinar la razón de esta actitud sensible, tensiona-

Früber Adel. Studien zur Politischen Fübrungs-schicht im Fränkisch-Deutschen Reich wom 8. bis 11. Jabrbundert, Stuttgart, 1973. La sistematización de esta serie de cuestiones la llevó a cabo el propio Karl Bost de una forma extremadamente coherente y original en su estimable obra Die Grundlagen der Modernen Gesellschaft im Miltelalter, Stuttgart, 1972.

3 Sobre el sentido y el carácter de la organización feudal véase J.E. Rurz Do. MENEC, *Système de parenté et théorie de l'alliance dans la societé catalane (env. 1000-env. 1240) s en Revue Historique, 1979, vol. 532, p. 305-325. Acerca del carácter simbólico y del sentido diferencial del universo aristocrático en la época feudal sobre su mundo y su morada, véase J.E. RUiz DOMENEC, EJ origen de la obra de arte feudal, Bellaterra, 1979. Según se desprende de la investigación que allí lleve a cabo, los feudales crearon un universo de reglas, cuyas sucesivas transformaciones internas, de orden dialéctico, alteraron el contenido de su propiedad como lo que eran. El razonamiento de la utilización de un lenguaje, en ocasiones proteico, como el que sobrecargadamente allí necesité utilizar, y, ocasio. nalmente aquí debo asimismo emplear, se intentó justificar e incluso legitimizar en aquel discurso estético. Por ello mismo no me extenderé aquí en este propósi. to, considerándolo planteado ya. 
da. Es la nueva morada hábilmente sugerida que destrona la antigua ética aristocrática y el orgullo de casta vinculado a la tierra ${ }^{4}$.

Indudablemente, al trazar este nuevo significado de la guerra Bertran trata de reconciliar la tensión social existente en el suelo europeo desde mediados del siglo XII. La perturbación ha sido el resultado de una profunda inflexión en el ritmo histórico, que ha modificado la vida económica, ha perfilado un nuevo contenido del poder, ligado con la corte, y ha destruido los sistemas normativos feudales ${ }^{5}$.

$4 \mathrm{El}$ aristócrata construye su existencia ligada a un praedium libertatis, a una certa habitatio, como vivienda social, política, cultural, pero también como morada existencial. C. Karl Bost., Die anistokratische Struktur der mittelalterlichen Gesellschaff, cit., p. 31-33. Del mismo modo, Hatto KALFELZ, op, cit. p. 19 y ss. Estos autores señalan además el importante cambio que se observa en las fuentes entre finales del siglo XII y principios del siglo XIII, donde como literalmente ha escrito Bosl «dass es ohne nobilitas mentis keine nobilitas carnis geben Könnes. Esa alteración o ruptura afecta al conjunto de la época, a la que el propio Karl Bosl denomina aAufbruchsepoches, debido a que el proceso de intromisión del pensamiento de la Iglesia sitúa a la aristocracia delante de sí, produciéndose una anhelante necesidad de justificar, es decir, legitimizar, su preeminencia social al margen de estos valores. Inteligentemente lo ha logrado observar Bosl cuando escribió eFragwürdig wurde die nobilitas corporis durch das Eisetzen rationalen Denkens im theologisch-philosophischen Raum der Scholastik, seit der Trennung von Weltlichem und Geistlichem, von Naturlichem und Übernaturlichem, dessen magisch-kultische Verbundenheit ja die Heiligkeit des Geblüts ausmachtes, op. cit., p. 32.

La mutilación del sentido utópico de la aristocracia que se liga al valor de la tierra, produce una colisión trágica que queda asumida perfectamente en las páginas de la Chanson de Roland. Véase J.E. RUIz DOMENEC, La contrautopia arcaica en la a Chanson de Rolands, VIII Congreso de la Société Rencesvals, 1978.

5 Las contradicciones del feudalismo son patentes a finales del siglo XII. Sobre este problema se han escrito demasiados trabajos, muchos de ellos superfluos. Lo mejor sin duda se lo debemos a Georges DUBY, que, en su Les trois ordres on l'imaginaire du féodalisme, Paris, 1978, p. 387-393, traza un cuadro modélico de este problema. Ahora bien, tratar de describir ese estado, y fundamentalmente ofrecerle una razón, ha sido un largo debate que no está aún cerra. do. Es de justicia señalar las tres grandes obras que le han ofrecido una respuesta de conjunto a este problema, proponiendo claramente la naturaleza de esta ecrisisa de los sistemas normativos feudales. En primer lugar debe señalar la inteligente tesis de Fr. HeER, Aufgang Europas. Eine Studie zu den Zusammenhangen zwischen politischer Religiosität, Frömigkeitsstil und dem Werden Europas in XII Jahrhundert, Wien-Zurich, 1949. Creo que esta obra, en su conjunto, ofreció una convincente idea de la naturaleza de ese gran suceso que tuvo lugar a finales del siglo XII, $y$, como una obra representativa de cierto spesimismo historicista, debe analizarse en las circunstancias políticas que parece que hicieron posible el ocaso de la sociedad feudal. En segundo lugar, la atractiva tesis de G. WEBER, Gottfried von Strassburg "Tristanv und die Krise hocbmittelalierlichen 
En pocas palabras, nos encontramos entre $1190-1195$ con dos fenómenos en apariencia diferentes pero sustancialmente idénticos: 1) Una acción militar en la esfera real, la batalla de Alarcos, que se halla profundamente marcada por las novedades técnicas y sociales que afectaron al sentido de la guerra. 2) La presentación clásica, pero a la vez renovadora, de esa gran aventura del destino que significó trazar una imagen estimativa de la guerra. La conjunción dialéctica de ambos elementos convirtió la naturaleza de estos esirventés» en un arma ideológica de la clase dominante, en especial para justificar la conquista de la periferia de su conjunto territorial, injustamente sometida a las armas feudales y al carácter de ocupación que van a poseer los ejércitos de las monarquías occidentales ${ }^{6}$.

$\mathrm{Y}$ con esto llego a la intención del poeta. La interpretación eingenua» de estas poesías diseca el carácter propagandístico y de exigencia de legitimización moral que ellas encierran. Su relativa objetividad no hace menos verdaderas las intenciones que ocultamente plantea. Dejando aparte, por el momento, las algo complicadas implicaciones políticas del personaje, puedo ciertamente afirmar que estos esirventés», más que ninguna otra obra, cuentan la historia de la adopción de los ideales caballerescos como los nuevos sistemas de valores de la clase dominante?

Weltbildes um 1200, Stuttgart, 1953. Y en tercer lugar, la muy significativa tesis que trató de sintetizar y ordenar el Erich KOEHIFR, Ideal und Wirklichleit in der Höfischen Epik, Tübingen, 1970 (uaducción francesa, París, 1974).

6 La historia social se preocupa en la actualidad de determinar el significado y los motivos de esa traslación de la guerra y la agresión feudales del centro de su sociedad a la periferia. El interesante ensayo de D.C. DougLAS, The Norman Achievement, 1050-1100, Berkeley, 1969. plantea el origen de esa verdadera eteología de la guerra que inspiró, legitimizándola, la agresión sobre la periferia. En esta línea lo continúa en un breve pero agudo ensayo G. BARRAcLOUGH, ¿Deus lo volt? ? en The New York Review of Books, 21 (1970), p. 12-17.

7 Este planteamiento, aún no sistematizado, tiene la gran ventaja de contestar las cuestiones sobre la naturaleza de la aguda transformación en el universo de las creencias de la clase dominante que no habían sido contestadas por la teoría clásica de un Marc BioCH, por ejemplo. Como es sobradamente conocido, este autor en su estimable obra La sociéte féodale, Paris, 1966, se mueve en un foco interpretativo sobre la unidad nobleza/caballeria que impide comprender el proceso dialéctico de intromisión de este nuevo sistema de valores, y, consecuentemente, su análisis autónomo. Algunos trabajos han visto ya este problema; por ejemplo el interesante ensayo de Daniel ROCHER, " "Chevalerie" et littérature "chevaleresque"s, en Etudes Germaniques, 1966, p. 165-179, y 1968, p. 347. 357. Sobre el problema de la caballería en su conjunto, lo mejor es remitir a la introducción que lleva a cabo Arno BORST, Das Rittertum im Mittelalter, Darm- 
En efecto, Bertran profundiza en el análisis de la ruda actitud que desarrollaron los últimos feudales sobre su mundo para poder mantener su preeminencia social, aunque fuera a costa de abandonar su universo de creencias y de mitos. Por esta razón la dimensión que le ofrecerá al sentido de la guerra es un hecho fundamental, al ser aquella el elemento activo y creativo de la sociedad feudal. Debemos entender que para la nobleza feudal la sustancia específica del acto guerrero es el acontecimiento nuclear al que referirá el resto de sus aconteceres, e incluso las leyes universales de la naturaleza. Configurar en esta dimensión el sentido de la batalla de Alarcos supuso para Bertran poder asumir hondamente la recepción del nuevo contenido de la guerra que los ideales caballerescos exigían. De ese modo, la guerra traspasó los contornos sociales y culturales que la había caracterizado en épocas anteriores para hacerse evidente como un acto total que engloba todo lo omniinclusivo que esta sociedad necesita ${ }^{8}$. En el universo del roman, o, más aún, en ese espacio todavía resistente de la epopeya, se necesita expresar e irradiar el esfuerzo de toda la sociedad para imponer una moral a la acción militar?. Pero nadie, ni en la poesía ni en el roman supo, mejor que Bertran, exponer ese momento de absoluta gravedad, transfigurado y henchido donde los hombres sactificaron su vida, santificándola,

stad, 1976, p. 1-17 (con abundante y selecta bibliografía); y a J. BUMKE, Studien zum Ritserbegriff in 12. und 13, Jahrhwndert, Carl Winter, Heidelberg 1977. especialmente también aquí la introducción, p. 9-19. Un cuadro atractivo, pero un tanto atomista, es el que traza F. CARDIN1, eLa tradizione cavaleresca nell'Occidente medioevale. Un tema di ricerca tra storia e "tentazione" antropologiches, en Quaderni medioevali, 1976, p. 125-142.

El sólido edificio cronológico que ha trazado Georges DuBY en Les troies ordres cit., p. 352-370, permite extender ya un tipo de argumento sobre el tratamiento de las fuentes, y mucho más hondamente sobre la necesaria comprensión de que la caballería es un modelo imaginario de inspiración externa a la sociedad aristocrítica. No voy a insistir aqui en los argumentos teóricos que me han permitido establecer este problema, y desde luego no voy a trazar las razones empíricas que legitimizan esta tesis. Para el problema en su conjunto, véase J.E. RUIz Do. MÉNEC, ELa idea della cavalleria medievale come una teoria ideologica della societàs, en N.R.S.I., 1981.

8 Así lo ha visto y lo ha estudiado con ejemplaridad, Georges DuBY, Le dimanche de Bouvines, Paris, 1973.

9 Para la moral del guerrero del siglo XII, véase Georges DuBY, «Guerre et société dans l'Europe féodales, en V. Branca, ed., Concetto, Storia, Miti i lmmagini del Medioevo, Firenze, 1973, pp, 449-482. Especialmente apartado segundo La morale des guerrierss, cit., pp. 473-482. Sobre el cuadro ideológico que presenta el origen del roman, cfr. J. LE GOFF, «Naissance du roman historique au XII siècles, Nouvelle Revue francaise, 1972, pp. 163-173. 
para el orden social y para la preeminencia imaginaria. De ahí que la precisión que impone a su lenguaje poético sobre la guerra en torno a 1190 no presta únicamente direccionabilidad a los aspectos estrictamente literarios, sino también a los soportes sociales e ideológicos. Así, la guerra adquiere una formas diferente de la que había tenido en la época feudal. Para entender a Bertran es imprescindible arrancar de este principio. Podríamos reintroducirlo en un análisis general de la aguda intromisión de los valores caballerescos en el mundo feudal. Pero ahora he de atender a su aspecto específico con el que instaura una verdad para el sentido que va a poseer la guerra a finales del siglo XII. Porque el poeta del Peirigord edifica sobre su concepción de la guerra todo un universo imaginario, incluso una concepción estética. Una obra de arte ${ }^{10}$.

Eso explica, en mi opinión, por qué se manifiesta en estos osirventéss como un excelente narrador de esa serie de acontecimientos que constituyen la cotidianidad agónica de la clase dominante en las tres últimas décadas del siglo XII" ${ }^{11}$. Intuiciones brillantes, un rico vocabulario y sobre todo esa penetrante devoción por lo que trata de esbozar, son los fundamentos de su obra. Pero esta actitud, que

10 Puedo ilustrar esta afirmación que a algunos les parecerá aún hoy parad6jica, y sin duda alguna atrevida, volviendo una vez más al pensamiento de Nietzche. Para él Die Kunst ist mehr wert als die Wanrheit: das will heissen: sie kommt dem Wirklichen, dem Werdenden, dem 'Leben" naher als das Wahre, das Festgemachte und Stillgestellte. Die Kunst wagt und gewinnt das Chaos, die verborgene, sich uberstromende, unbewaltigte Uberfülle des Lebens, das Chaos das zunächst wie blosses wirres Gewijhl erscheint und aus bestimmten Grunden auch so erscheinen musss. El resumen y la interpretación es de Martin HeIDEG. GER, Nietzsche, Verlag Günther Neske Pfüllingen, 1961, pp. 568. ¿Puede creerse que el significado que Bertran le confiere ahora a la guerra, y fundamentalmente a la batalla, asume ese ordenamiento del caos? En ese aspecto sería mejor comparar la necesidad que tuvieron los feudales a finales del siglo XII de realizarse hondamente en la acción guerrera, sea en la poesía, en la narración novelesca, o en la epopeya, sea en la propia realidad, con la acuciante exigencia de dar un orden a una sociedad que estaba en el límite de su existencia creativa. El absoluto rigor formal que impusicron a sus actos guerreros facilita la comprensión de que la guerra es un verdadero arte, porque ella al igual que él, en el decir de Nietzsche es «ein Überschuss und Ausströmen von blühender Leiblichkeit in die Welt der Bilder und Wünsches (cfr. M. HeIDEGGER, íbidem, p. 568).

11 Georges DUBY, Les trois ordres, cit. pp. 389, lo ha dejado perfectamente claro cuando ha escrito sLa réalité du XIIe siécle finissant, c'est aussi la chevalerie qui plastronne, engoncée dans ses armes, ses armures, ses armoires, inquiete, menacée par la montée des parvenus, le sachant bien et sachant mieux encore que les fondements de sa supériorité fléchissent, qu'elle ne serait plus rien sans les bienfaits du princes. 
había sido levemente insinuada en el penoso peregrinar poético y existencial entre 1173-1185, alcanza ahora una conciencia expresa, directa, representada por la intensidad de su deseo de querer afirmar a la nobleza en su acción militar. De ese modo logra trazar su naturaleza exacta, a pesar de las dificultades que le impone la lengua en la que se expresa, profundamente marcadas a la hora de precisar el ritmo que necesita imponer a su poesía guerrera ${ }^{12}$

Históricamente hablando, en la bruma de estos años difíciles del poeta, tendrá lugar una esegunda aventura, también imposibles ${ }^{13}$. Esto es lo que se hace evidente en esa voz alucinada y estremecida, llena de orgullo y de riqueza moral, de violencia y de atributos de dominio que legitimiza la realización de la aristocracia en la aventura caballeresca por excelencia: la acción militar. Eso es humano, después de todo. Si Bertran, hacia 1190, advierte la imposibilidad de abrirse al mundo en el interior de su sistema de parentesco, es natural que ambicione la ruptura de él como el criterio de medida de la conducta humana, y que sostenga que el impulso turbulento es el soberano de este mundo. En este sentido, nuestro poeta busca justificar su existencia, y con ella la de toda la clase social a la que pertenece, formulando una verdadera apología de la acción militar. De los antiguos signos en donde se encontraba la razón de la existencia aristocrática sólo quedan restos calcinados, arcilla pisada, o ese sonido triste que solloza entre una congoja por no ser señor y una culpabilidad por querer ser señor al margen de la lealtad en el silencio.

Su poesía sobre la guerra no es simplemente un desasirse en las claridades que permitía la concupiscencia ${ }^{14}$; es también un deseo

12 Esta cuestión plantea un debate lingüístico, y quizás también de géneros literarios. Como han señalado J.A. HuISMAN, Neue Wege zur dichterischen und musikalischen Tecbnik Walthers von der Vogelweide, Utrecht, 1950; y D. RoCHER, " "Chevalerie" et littérature "chevaleresque" s, cit., pp. 350 y ss., el ritmo es diferente según el género o la lengua que se emplea. Este último autor ha es. crito ale poeme lyrique est ignorant de la guerre, seul savant de l'amour (pour laisser de coté la poésie de croisade, le lai religieux, dont la finalité est limpide: mai la forme aussi est autre, celle du lai, celle encore de l'Elegie de Walther, qui, par son metre et son compte de mesures rappelle délibérément, et l'épopée na. tionale, et la poésie politique)s.

13 La primera, cronológica y temáticamente hablando, fue el intento de realizarse cimaginariamentes en la mundanidad del parentesco. Cfr. J.E. RUZZ Do. MENEC, La aventura imposible de Bertran de Born, cit.

14 Etienne Gilson, La théologie mystique de Saint Bernard, Paris, 1969, p. 200 ha escrito al'amour courtois est l'expression poétique de la concupiscences. 
hondo de penetrar más allá de lo que el estado absoluto de alienación les había conducido. La descreencia en los valores aristocráticos y en la misma operatividad del sistema de parentesco, sitúa a Bertran en la necesidad de una reinterpretación de la existencia de la clase dominante al margen de las normas que imponían la teoría de la alianza laica. Pero al reinterpretarlas busca una certeza en la condición existencial de la clase de los guerreros. De esta forma aúna, por un lado, la necesidad de superar la propia condición existencial de la aristocracia y, por otro, la exigencia incontrovertible de convertir a los bellatores de la tradición ideológica de la Iglesia en auténticos guerreros, es decir, en caballeros ${ }^{15}$. En ese sentido indirecto sobre el mundo y sin la necesidad de reorientar su búsqueda hacia la irrealidad de un bosque sin sendas, y probablemente abstracto, como el de Brocelandia ${ }^{16}$, Betran sostuvo la existencia de una clase de guerreros y legitimizó su turbulencia.

Pero hay más. El brillo de su imaginación trazó ahora un nuevo amanecer para los feudales: dorado como gótico, escarlata como festivo, amarillo como el fuego de la fe que le impulsaba. Hacia 1190 la cultura feudal murmura su desaparición. Brocelandia es una tentación fácil. La mirada fija en el Graal es la piedra más absoluta de un anhelo de la inmensidad glacial. Pero Bertran huye de todo esto. Quizás de un modo inconsciente y muy a pesar suyo, pe-

Una honda reflexión sobte este tema en Julius SCHWIETERING, Mystit und Höfische Dicbtung im Hocbmittelalter. Tübingen, Max Niermeyer Verlag, 1962, especialmente capítulo primero *Der Tristan Gottfrieds von Strassburg und die Bernhardische Mystiks, pp. 1-35.

is Cfr. J. BatanY, eDu bellator au chevalier, dans le schéma des "trois ordres" (etude sémantique)s, en Guerre et Paix, Paris, 1978. Actes du Cle Congrès national des Sociétés savantes, pp. 23-24.

16 Cfr. J. Le GOFF - P. VIDAL-NAQUet, oLévi-Strauss en Brocéliandes, en Critique, 325 (1974), pp. 541-571. Especialmente p. 555. Estamos aqui de nuevo ante los problemas más acuciantes que se le plantearon a los feudales a finales del siglo XII. El sentido de la aventura en ese bosque - que como dice Le Goffeaucun arbre n'est décrits, tiene que ver con la esencia de aquello que es y de aquello que no es. Relación dialéctica entre una realidad que no tiene consistencia eidética, y una idealidad que busca comprenderse en un sentido arquetípico. Pero entendieron realmente los autores de los roman la idea de los arquetipos como sustitutivas de su universo en crisis? El profundo análisis que hace el profesor Erich KOEHIER, op. cit., pp. 7 y ss., sobre la realidad histórica y el ideal caba. lleresco en la materia bretona del rey Arturo permite entender la circunstancia material de este mundo microcósmico, donde se encerraron los scaballeross para reemplazar por la sola acción de la aventura el concepto de su mundo: he ahí la necesidad de la abstracción del conjunto geográfico. 
ro aun así con plena responsabilidad, secunda la separación entre la realidad y el mundo alegórico, sosteniendo o recrudeciendo las condiciones que dieron pie a la crisis de los sistemas normativos feudales: la emergencia de la corte y la figura del principe ${ }^{17}$. La pérdida absoluta del universo feudal no le lleva a una peregrinación por la esfera imposible, ni siquiera dirige su quête a la necesaria pérdida de la realidad, sino que amplía el campo exacto a la realidad misma. De nuevo aquí Bertran de Born no es Wolfram von Eschenbach. Su mirada fija en ese espacia brillante y cruel que permite arder entre fuegos de tarde la pasión, la desbordante pasión de los feudales, de los últimos feudales, la guerra.

Bertran de Born imaginó como nadie supo hacer ni antes ni después (quizás hasta Georg Trakl) ese instante de verdad que la nueva concepción de la guerra y de la agresión tenían ${ }^{18}$. Claridad de ese momento de verdad cercano a la muerte. Pero también libertad para convertir el objeto central de su vida en algo conternplativo: estéticamente hermoso, socialmente legítimo. De ahí que trazara las tenebrosas líneas de la idea del coraje unida a un universo nuevo, inundando las palabras de significación, los gestos de intensidad, los silencios de realidad ${ }^{19}$. Sin necesidad de inscribir el valor en la virtud mágica, Bertran hizo posible el arrebato entusiasmado que la acción militar exigía ${ }^{20}$. De este modo tan sencillo, constituyó

17 Como ha descrito acertadamente Georges DuBY aLa réalité du XIle siècle finissant, c'est la cour..., (Les trois ordres ou l'imaginaire du féodalisme, cit., p. 389).

18 J.E. RUIz DOMÉnEC, eGuerra y Agresión en la Europa Feudal. El ejemplo catalán*, en Quaderni Catanesi di Studi classici e Medievali, II, 3 (1980), pp. 265-324.

19 La historia del coraje está por hacer. Algunos bocetos interpretativos se pueden encontrar en Philippe Contamine, La Guerte au Moyen Age. Paris, P.U.F., 1980, pp. 406-418. Este podría ser el comienzo de una honda descripción de una de las cuestiones más importantes del análisis de la guerra, y del comportamiento guerrero, en la época feudal. Existe un planteamiento muy condensado, pero excelente, en la teoria de Georges DUBY, Le dimanche de Bouvines, cit. pp. 25 y ss, Cfr. infra.

20 sin embargo, este auto-olvido no tiene nada que ver con un estado privativo, pues su origen está en el volverse hacia la cosa y el espectador lo realiza como su propia acción positivas, según Hans-Georg GADAMER, Wabrheit und Metbode, Tübingen, 1975, p. 120. Este es el nudo de la cuestión de un problema grave. Eugen FINK, Vom Wesen des Entbusiasmus, cit., pp. 20 y ss., analiza el fondo del entusiasmo y las condiciones necesarias para su realización en la esfera existencial y psicológica. Para una comprensión de estas necesidades en la cultura feudal, véase J.E. RUIz DOMENEC, El origen de la obra de arte feudal, cit., pp. 18 y ss. 
el primer ejemplo, y el más hondo, de un canto a la batalla como si realmente fuese una fosforescencia azul.

Pero para la sociedad de finales del siglo XII ( $y$ nuestro poeta es consciente de ello) la «batalla no es la guerra ${ }^{21}$. Los metales, que se encuentran en ese espacio ordenado, agonizan distantes en el último juego mundano que la sociedad acepta ampliamente ${ }^{22}$. Un juego de sonidos contrapuntísticos, mesurados, góticos. Entre ruinas y desolaciones, Bertran logra centrar ese momento donde el pensamiento traza la gran mentira: sustraer el temor que invadió a la aristocracia feudal a finales del siglo XII. Y una de cuyas razones, quizás la más decisiva, fue la definitiva conversión de la acción guerrera en una acción caballeresca ${ }^{23}$. Este hecho implica que la poesía de Bertran se transforme hacia 1190, y por poco tiempo además ${ }^{24}$

Un problema de carácter especial es si el proceso de salida-de-sí del guerrero en la época feudal debe considerarse como un elemento más de un hacer mágico y mítico, o, por el contrario, se opera ya en el mismo sentido de la reflexión estética (y moral). Es innegable que en el periodo carolingio el entusiasmo del guerrero obedecía a su vinculación a la esfera mágica del poder (véase por ejemplo la acción de Luis el Piadoso frente al muro de Barcelona, en J.E. RUIz DOMENEC, -El asedio de Barcelona según "Ermoldo el Negro". Notas sobre el carácter de la guerra en la Alta Edad Medias, en Boletin de la Real Academsia de las Buenas Le. tras de Barcelona, 1979, pp. 149-168. Sin embargo creo que en el periodo final de la época feudal, cuando Bertran de Born le está dando forma a sus esirventés» sobre la guerra, el entusiasmo es ya un ealgo» inherente a la creación eartísticas misma, al valor estético fundamental, al contenido moral de su reflexión. En una palabra, es un hecho imaginario. Una obra de arte. Más tarde tendremos ocasión de ver qué consecuencias hermenéuticas posee esta tesis.

21 Cfr. G. DuBY, Le dimanche de Bouvines, cit. p. 145.

22 El otro juego, el del amor, es cortesano e interior. Incluso tiende hacia el desprecio del mundo exterior. Sobre la idea de juego véase E. FinK, Spiel als Welzsymbol, Stuttgart, 1960, H.G. GADAMER, op. cit., pp. 97 y ss. y J. HuIzINGA, Homo ludens, Madrid, 1970. La forma objetiva de un trazo agonal en la esfera de las realizaciones internas, por ejemplo cortesanas, son planteadas ingeniosamente por Jean Duvignaud, Le jeu du jeu, Paris, Balland, 1980.

23 Un hecho que tuvo lugar hacia la segunda mitad del siglo XII como consecuencia de una transformación profunda en la morfología y en la función del armamento. Cfr. V. CIRLOT, El armamento catalán de los siglos XI al XIV. Bellaterra, 1980. Tesis doctoral (en prensa).

24 Es fácil describir esta batalla que tiene lugar en el seno de lo imaginario de la última fase de la feudalidad europea. Hacia 1225 , fecha probable, aunque todavía discutida del importante ciclo final del mundo feudal, el Lancelot en pro. sa, las circunstancias específicas de la naturaleza de la acción militar han sido absorbidas por el mundo ordenado de la sabiduría eclesiástica. J. LE GOFF, La civilisation de l'occident Médiéval, Paris, 1965, sugirió la atractiva tesis de que todo fue un conflicto entre la eprimera y la segundas función, que culmina, dice tex- 
en un llanto abierto, trágico, sobre el destino de esa sociedad y se abra a la errancia más penctrante. Por eso es capaz de trascender de su situacionalidad existencial, específica y abrirse a la naturaleza misma de esa turbulencia, a mitad de camino entre una necesidad social y un objetivo material. Tales acciones en la poesía de Bertran afirman que la visión mantenida hasta el momento presente de querer presentarlo como un poeta de la guerra es cuando menos equivocada ${ }^{25}$. Bertran no describe la naturaleza esencial de ese acto nuclear, la guerra y la agresión a finales del siglo XII con la carga de desintegración que lleva en su seno ${ }^{26}$, sino que quiere describir el sentido existencial de un acto global de civilización donde se cohesiona la *buena sociedad*, que en ese momento es rigurosamente

tualmente, en que eel poder sacerdotal, bajo una forma por lo demás muy depurada, ha absorbido el valor guerreros. La cuestión de si los valores estrictamente mitraicos, absorben y superan, en las primeras décadas del siglo XIII, a los que son propios de Varuna, se describe como una secuencia de alternativa, cuando yo lo creo nada más como un guía de inspiración artística. Bertran está al final no porque represente el último sentido del valor laico sobre el eclesiástico (debido a que la caballería, toda clla, es de naturaleza eclesiástica) sino porque la distinción dialéctica Mitra-Varuna está aún presente en su sentido tensional, y, consecuentemente, en la esfera de emuertes (cfr. infra). A partir de él, ambos aspectos se describirán como la intemporal estructura geométrica de un mundo (el escolástico-gótico) que analiza la comunidad política como dual, infiriéndose en el comportamiento y dándole un sentido lineal: a lo que pone fin la escolástica es naturalmente a la aventura como búsqueda de identidad, pero no al carácter concupiscente de la guerra y la agresíon. Pero ahí colisiona Bertran con su mundo, porque en la década de 1190 va a tener la primera batalla en sentido abierto. litúrgico, ritual, incuestionable: real. Los valores simbólicos que poseían la conjunción de ambas funciones ya carecerán de operatividad. Su aullido triste es el comienzo del mito narrado en forma de ciencia. Medido.

25 Lo que debe interesarnos de estos juicios sobre Bertran no es tanto su contenido como las distinciones mediante las cuales son expresados. Mare BLOCH, $o p$. cit., pp. 409 y ss. lo distingue como el paradigma de la vida noble realizada en la guerra, a pesar de que el poeta se presenta lleno de una eprécision visuelle et le bel élan, qui tranchent avec le fadeur d'une poésie ordinairement plus con. venue, sont la part d'un talent au-dessus du communs. Más ponderado fue el insigne estudioso $\mathrm{E}$. HOEPFFNR, Les troubadours dons leur vie et dans leurs oeuvres, Paris, 1955 cuando escribió, p. 124, aPoète de la noblesse du Limousin, Bertran est donc avant tout le chantre de la guerre et des batalless. De igual forma lo concibió A. VISCARDI, Le letterature d'oc e d'oil, Milano, 1967, que dijo de él que era eil poeta delle armis (p. 151).

26 En especial por la aparición de las earmas ignóbiless en el contacto. Véase este problema en Georges DUBY, Guerre et sociêté dans l'europe fëodale, cit., Pp. 466 y ss. donde analiza las razones que permiten dar un sentido esubversivos y, además, destructivo, a la acción militar en la segunda mitad del siglo XII. 
cortesana. Ese acto es la batalla como rito pero también como objetivo para la legitimización de la naturaleza de la aristocracia como una «casta de guerreros». Por eso, al trazar la fisonomía de la batalla, y no de la guerra, Bertran es capaz de trascender de la pura realidad que esta última llevaba en su seno y someter al aristócrata a la servidumbre de un orden estricto que ya no lo imponen ni las normas del parentesco, ni los valores estrictamente paganos de la virtud aristocrática, sino simplemente la acción organizadora de la corte y de su espacio visual especifico. La batalla, y no la guerra, es el acto de re-presentación mundanal de la nueva realidad del poder de finales del siglo XII: el poder del rey. Sobre esta textura fresca y absoluta siente la tangibilidad de su mundo y de su clase. En pocas palabras, este trovador del Peirigord no intentó nunca poetizar la razón de la guerra, sino de la baralla. Y al hacerlo, la describió como un mero objeto del impacto ambiental de su circunstancia social, cultural e ideológica. De ahí que no nos quepa la menor duda de que Bertran de Born lo que hizo estrictamente fue darle fisonomia y estructura al sonido de la batalla.

A decir verdad, todo comenzó con la búsqueda de una nueva esfera-de-propiedad ( = Eigenbeitsphäre) ${ }^{27}$ que Bertran la encuentra en la corte y sobre todo en la figura del rey ${ }^{28}$ :

\section{Miei-sirventes vuolh far dels reis amdos}

Puesto que el rey es ahora tan altamente exaltado por encima del mundo entero, cualquier cosa del mundo dependerá de su infinito caudal de realización. De su largueza sabia y ordenadora ${ }^{29}$ que hace posible la regeneración material, social y humana:

Qu'en brieu veirem qu'aura mais chavaliers:

Del valen rei de Castela, N'Anfos,

qu'auch dir que ve a volra soudadiers;

27 Sobre el concepto y su realidad, véase Robert KL.EIN, AAppropiation et aliénations, en La forme et l'inteligible. Ecrits sur la Renaissance et l'art moder. ne, Paris, 1970, pp. 459-472.

28 Edición Carl Appet, op. cit., núm. 37, pp. 88-89. La traducción castellana que ofrezco es la de Martin De Riquer, op. cit., núm. 138, pp. 734.736. Algunas puntualizaciones sobre el carácter de la poesía se encontrarán en esta última obra.

29 Según señalé en J.E. RUIZ DOMENEC, La aventura imposible de Bertran de Bom, nuestro poeta traza una imagen del rey adornada con tres funciones determinadas: 1) El verdadero señorío. 2) La autenticidad participativa, y 3) el orden correcto $\mathrm{y}$ absoluto del cosmos. 
(pues en breve veremos que habrá más caballeros. gracias a don Alfonso, el valiente rey de Castilla, de quien oigo decir que viene y querrá mercenarios).

La dependencia de la nobleza guerrera con respecto al mundo de la corte es tanto una exigencia ideológica como una necesidad material, La imagen del noble mercenario ${ }^{30}$ es legitimada en el universo poético de Bertran en términos tales que se puede afirmar que solo ellos son los auténticos portadores (= trägerns) de los nuevos hábitos militares, cortesanos y caballerescos. Este es el verdadero esquema social que la poesía trovadoresca plantea si hemos de creer a Erich Köhler. Según este autor los soudadiers serían los portadores estrictos de los valores de la kjeuneusse y de la turbulencia ${ }^{31}$.

Pero siendo así, los caballeros deben entender el mundo a la luz del verdadero señor, el rey. Él es el fundamento de un pacto histórico. Por lo tanto, cualquier cosa del mundo debe pertenecer de hecho a la historia de este fundamento. De ese modo, el rey se convierte en la clave no sólo para darle un contenido estricto a la batalla, sino también para desarrollar las novedades técnicas, tácticas, psicológicas y morales de la acción militar. La participación en la magnificencia y la largueza del rey explica la posibilidad de apertura mundanal que el noble tiene al convertirse en caballero:

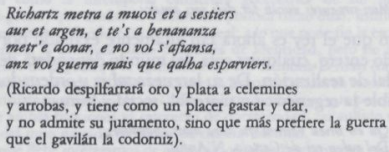

30 Sobre los mercenarios y su significación en la sociedad de la segunda mitad del siglo XII, Georges DUBY, Guerre et sociêté dans l'Europe féodale, cit.. pp. 466 y ss. Vease también J. BoussarD, eLes mercenaires au XII siècle. Henri II Plantagenet et les origenes de l'armée de métiers, en Bibliotheque de l'Ecole des Chartres, vol. 106, 1945-1946, pp. 189-224 y Philippe CONTAMINE, op. cit. pp. 192 y ss.

31 Cfr. E. KOEHILR, «Sens et fonction du terme "jeneusse" dans la poésie des troubadorss, en Melanges $R$. Crozet, 1966, pp. 569 y ss. En todo caso ésta ha sido una de las constantes del sabio filólogo alemán, como puede verse en la reu. nión de sus trabajo llevada a cabo por Mario Mancini, bajo el título Sociologia della Fin'Amor. Saggi Trobadorici, Padova, 1976, especialmente, pp. 1 y ss., 257 y ss. El valor de esta interpretación lo lleva a cabo el propio Mancini, p. XXII-XXVII. 
En esta situación la batalla alcanza un nuevo contenido, inscribiéndose en la misma naturaleza de la crisis del sistema feudal. Literalmente, la batalla significa el propio umbral de la regeneración en la paz. Ese estado puede describirse mediante un acto litúrgico, ritual. En el momento que se lleva a cabo la batalla, las cosas que componen el mundo desaparecen para dar entrada a una transmutación cósmica, casi sagrada. Es el comienzo absoluto de *algo* que Bertran de Born necesita plantear para saber.

En efecto, para nuestro poeta el inicio mundanal de la nueva nobleza caballeresca debe ser universal. Hacia 1190 se constata con facilidad que no es posible establecer correlación alguna con el mundo anterior. No es posible retornar. La ambigüedad mundanal del aristócrata ha terminado por situarle ante la necesidad de aceptar de lleno la utopía de una nueva realidad social e imaginaria: ese espacio plateado donde florecerá la nueva cultura gótica y el sonido de la batalla. $\mathrm{La}$ idea es verdaderamente central en los textos trovadorescos, y en especial en Bertran. Suele venir acompañada de la aceptación sin reparos de la imagen de la corte y del rey. De ambos dependerá la nueva forma de realización de la aristocracia, convertida ahora desde un punto de vista jurídico en nobleza y desde una perspectiva ideológica en caballería.

Pero hay más. La poesía de Bertran exige convertir al rey en el verdadero elemento de seguridad y la batalla en el significado más hondo de la comunicación humana y quizás sexual:
S'anduli li rei son pro ni coratjos, en bries veirem champs jonchats de quartiers d'elms e d'escutz e de brans e d'arzos $c$ de fendutz per bustz tro als braiers:

(Si ambos reyes son valientes y animosos, en breve veremos campos sembrados de pedazos de yelmos. de escudos, de espadas y de arzones y de (hombres) hendidos del busto hasta la bragas).

Como puede verse, aquí se desglosan los primeros síntomas de la concupiscencia. Esa extraña sensación sobre el sombrío contorno sólo se explica si logramos entender el enraizamiento del placer sexual que procura el acto de la regeneración militar. Y esto es concupiscencia. Designación absoluta de los valores que el ideal caballeresco había querido imponer desde las primeras décadas del siglo 
XII, y además como una teoría ideológica de la sociedad ${ }^{32}$. Así pues, al explicitar la situacionalidad mundanal del guerrero en medio del campo de batalla lleva a cabo la plena significación de la concupiscencia y contribuye a resolver la situación ecrítica» y contradictoria de la clase dominante.

Bastará con mencionar, al hilo de la propia presencia poética de Bertran, los dos núcleos sobre los que va a situar la concupiscencia como ejercicio absoluto de un poder, el del universo gótico. Bertran nos describe por un lado el inmenso vacío interior de la clase dirigente, de la aristocracia, cuando se siente despojada de su conciencia. Para presentar este cuadro, nuestro poeta se traslada a la esfera simbólica, aunque sea por una sola vez, y exclama: et arratge veirem anar destriers ( $=$ y veremos caballos vagando errabundos). Como es suficientemente conocido entre la aristocracia de las épocas arcaicas, el caballo simbolizaba la conciencia y fragua la situación exacta que imponía la determinación de labrar certeza a ese abismo grave que encerraba la acción guerrera ${ }^{33}$. De modo similar interpreta Bertran el arrebato de la turbulencia como una complementariedad exacta de la pérdida de la conciencia y del estado de concupiscencia en el que ha caído el guerrero feudal hacia 1190. Y dice:

\section{e per costatz e per pechs mainta lanza \\ e gauch e plor e dol et alegranza \\ Lo perdr'er grans e'l gazanbs er sobriers}

(y muchas lanzas (clavadas) en los costados y en el pecho/ y júbilo y llanto y pena y alegría. / Grande será la pérdida, pero mayor la ganancia).

Como puede verse, estos dos núcleos que definen la acción militar se hallan vinculados entre sí por una relación polar, es decir, en

32 Cfr. J.E. RUIz DOMENEC, La idea della cavalleria medievale come una teoria ideologica della societì, cit.

33 Desde un punto de vista simbólico el caballo es uno de los idiogramas de la sabiduría para el caballero y el que le transmite la inteligencia (cfr. J.E. CIRLoT, Diccionario de Simbolos, Barcelona, 1969, pp. 118-119. De igual forma el caballo es un elemento en extremo sacro en los pueblos de la Alta Edad Media. Alcanza pleno apogeo, según se ha podido demostrar gracias a los inteligentes trabajos de los arqueólogos y los iconografistas, en los pueblos germánicos y nórdicos, donde el caballo alcanza el punto más elevado como elemento del sacrificio. Cfr. K. HauCK, Zur Ikonologie der Glodbrakteaten: Formen der Aneignung Spatantiker ikonograpbischer Konventionen in Paganen Norden, Spoleto. S.S.C.I.A.M.E., 1976, p. 81-106. 
parte están en conflicto y en parte unidos. La diferencia decisiva que los separa viene determinada por la función que en ellos desempeña la propia historia del proceso imaginario de Bertran de Born.

Es la concupiscencia la que desglosa el propio placer que Bertran encuentra en esta polarización tensional: pérdida de la conciencia, turbulencia como rito. De ahí que consiga expresar en lenguaje binario las dos circunstancias de la batalla: por un lado el sentido de gozo (gauch) y por otro el de la alegría (alegrantza). El gozo quiere el otro ser de la concupiscencia, la alegría como sacrificio solemne, en forma de una transformación del eros del gozo en el âgape de la alegria ${ }^{34}$. El sentimiento ritual procura una diferencia absoluta que le lleva a la comunicación por la misma concupiscencia. No es aún puritanismo, ni siquiera represión de los instintos, es simplemente sepultar bajo una diferencia de amor y de odio el pacífico renacer del hombre en la batalla.

El carácter estrictamente histórico de la idea de la guerra hizo posible que se transfiriese la función de la realización humana de la esfera del parentesco a la de la articulación militar: a ese mundo triste que caracterizará a la clase social caballeresca a finales del siglo XII. Así fue posible además amalgamar la figura imaginaria que la

34 Desde luego, Bertran es plenamente consciente de este hecho. Su poesía prueba estrictamente esta teoría. Puedo ofrecer numerosos ejemplos. Baste aquí con otro, quizás más hondo en el criterio concupiscente que le conduce hacia su destino. La agonía que lleva dentro el poeta del Perigord sólo puede liberarse en la batalla. El sabe, más que nadie, que la concupiscencia es el único elemento que puede acoger abiertamente la nueva dimensión de la agresión. Buscar la felicidad de esta dimensión universal es definitivamente encontrar la luz en el sacrificio rojo, escarlata. Por eso dice, en mayo-junio de 1188 (ed. C. APPEL, núm. 28, pp. 72-74) Qu'ieu n'agra colps receubutz en ma tarja/E fach vermelh de mon gonfano blanc. Fijense que al introducir tácitamente los nuevos valores de la concupiscencia señala el enorme simbolismo de una ruptura del campo cromático, visual y auditivo, del mundo feudal: la tela blanca. El resplandor de este símbolo fundamental, el gonfalon, se ha transformado, rompiendo su equilibrio anterior. Ahora alcanza tres dimensiones plenamente asumidas en esta poesía: 1) La heráldica; la significación genealógica es sin duda alguna la traslación de los valores del parentesco a los de la filiación. 2) La ritual; el hundir el significado de un color blanco, pureza por ausencia, silencio, en uno escarlata, acción, sacrificio, abre el campo a su ambivalente necesidad de ser simbolizado; en el dorado, que armoniza la causalidad y la finalidad de una época: la gótica. 3) La sonora: el deshacer de un rumor quieto, en un ruido que será rojo, el silencio: gemido de los golpes y las heridas. Esta poesía, escrita, como ya se ha indicado hacia 1188 todavía no logra ofrecer un diseño instrumental-sonoro, pero adelanta las razones que exigirán desarrollarla, razones estrictamente imaginarias: la concupiscencia. 
Iglesia había impuesto con otras figuras procedentes de otros acervos culturales. A veces fue posible incluso algo mucho más importante: que la expectación histórica ante la acción militar pudiera incluir la expectación ante ese universo de reglas estéticas, sonoras. Y así, Bertran traza ya en este mismo sirventés ese pórtico blanco de posibilidades de la batalla:

\author{
Trompas, tabors, senberas e penos \\ et entresenhs e chavals blancs e niers \\ (Trompas, tambores, banderas, pendones, enseñas y caballos \\ blancos y negros)
}

Y aunque ese deseo estético ahora quede simplemente esbozado, le sirve a nuestro poeta para dar entrada a algo que era aún necesario: la justificación de las razones precisas, exactas, de una batalla. Esto no es ciertamente amor a la guerra sino concupiscencia. Bertran lo dice:
veirem en brieu, que'l segles sera bos, que om tólra l'aver als usuriers, e per chamis non anara saumiers jom afiatz $n i$ borges ses doptanza ni merchadiers que venha de ves Franza; aqui tólra volontiers.

(y el tiempo será bueno porque se quitará la hacienda a los usureros y las acémilas no podrán ir seguras por los caminos ni los burgueses sin sobresaltos ni (ningún) mercader que venga de Francia, antes bien quien robe a su placer será rico).

El análisis del significado de la batalla en Bertran de Born nos ha llevado a importantes discernimientos acerca de la naturaleza de la acción militar a finales del siglo XII. A precisar el carácter ilimitado del deseo sexual de dominio que es lo que convierte a la guerra en una acción concupiscente ${ }^{35}$. Pero aún hemos permanecido en el umbral de comprender el universo sonoro de la visión que Bertran desarrolla. Pero este es justamente el objetivo más intenso que quiere expresar el poeta de Auteford.

35 Cfr. Franco FORNARI, Psicoanalisi della guerra. Milano, 1970. J.E. RUIZ DOMÉNEC, ^Guerra y Agresión en la Europa feudal. El ejemplo catalán», en Quademi Catanesi di Studi classici e Medievali, 1980, pp. 265-324. 
En efecto, cuando Bertran de Born reivindica el carácter universal de la guerra implícitamente afirma que las diferentes formas que ha revestido la realización en el seno de las estructuras de parentesco desembocan finalmente en la agonía y en el silencio. El amor a la guerra que era consustancial en la edad feudal no excluía sin duda el deseo de muerte, pero no asumía la líbido de conforma. ción del placer que supone que todo el universo esté orientado estéticamente en la acción militar. Tal es la enorme exigencia que ahora se plantea Bertran. Toda su poesía de estos años es una intensa búsqueda para precisar no sólo la expectación ante el contenido de la guetra y su significación social e ideológica, sino muy especialmente la naturaleza misma del sonido de la batalla. La presencia de elementos libidinosos en las experiencias y las actividades más altamente espirituales del guerrero feudal (del caballero de la segunda mitad del siglo XII para ser más exactos) subyacen en la misma dimensión del carácter de la agresión de la tradición monástica y del riguroso examen de las fuentes patrísticas que ahora comienza a practicarse en el suelo europeo ${ }^{36}$. La importancia del universo sonoro que Bertran va a desarrollar termina por hacer inseparable, hasta prácticamente nuestros días, la dimensión de un acto guerrero y la interpretación de un sentido rítmico musical que se inscribe técnicamente en la articulación corpórea, espiritualmente en la condición existencial ${ }^{37}$. Por ello mismo, para que el supuesto de Bertran sobre la guerra sea universalmente válido debe unir la dirección de la acción militar al sonido mismo del nuevo contenido que tiene la batalla. Para realizar tal cometido se proveyó Bertran de abundantes instrumentos conceptuales provenientes de ese hábito gótico, en el decir de Erwin Panofsky ${ }^{38}$. A finales del siglo XII, la batalla como rito cré́ símbolos que conjugaban los elementos de la acción militar y que podían aplicarse de un modo universal al acontecimiento decisivo de la unión más honda del caballero con su destino existen-

36 Cfr. Karl Bost, Dio Grundlagen der modemen Gesellschaft im Mittelalter, cit., vol. II, pp. 345-351. Sobre el carácter agresivo del mundo monástico, véase Barbara H. ROSENWEIN, \&Feudal war and monastic peace: Cluniac Liturgy as ritual aggressions, en Viator, II (1971), pp. 129-157.

37 Así, los valores más permanentes en nuestra cultura han tenido, consciente o inconscientemente, una formulación musical. Esto que es algo obvio no ha sido tratado con profundidad por la historia social, aunque empiezan a configurarse algunos ensayos inteligentes. Véase, a modo de ejemplo Jacques ATTAU, Bruits. Essai sur l'économie politique de la musique, Paris, P.U.F., 1977.

38 Erwin PANOFSKY, Architecture gothique et pensée scolastique, Paris, 1974. 
cial. Tal es la enorme diferencia que media entre la idea de la guerra del siglo XI y el carácter concupiscente que alcanza a tener en la segunda mitad del siglo XII. No sólo son cambios tácticos, técnicos o militares, también existe una diferencia aguda debido a la actitud con respecto al universo sonoro. En la literatura del roman arturiano, por ejemplo, la caballería cobra una significación cósmica, sus leyes le confieren una realización eterna y la sabiduría divina que las orienta constituye el principio de la creación y de la salvación de estos caballeros. El nuevo ser-que-se-bace-en-la-guerra está ligado a esa atmófera de la que podemos sostener abiertamente que es gótica ${ }^{39}$.

Bertran de Born inaugura un extremo más hondo si cabe. Su voluntad de imponer una norma moral a los hombres y a la conducta militar traslada simbólicamente toda su realización al campo sonoro. Su poesía adquiere una dimensión de querer advertir una explicación del contenido mismo de la acción guerrera en los ritmos del universo. Y más exactamente en su destrucción. El sonido de la batalla es el ansia infinita de poder realizarse como caballero errante, engendrando entonces un campo de posibilidades absolutas donde el deseo de alcanzar la quietud por la intensidad del campo sonoro es negación consciente y absoluta del silencio 40 . En este punto es obvia la analogía con la ruptura de la intención heroica del Roland. Para ambos, el anhelo está situado, podríamos decir con Marius Schneider, en el límite del «plano acústico puro ${ }^{41}$. Pero mientras Roland desespera por vencer la tentación de comunicarse con el mundo, satisfaciendo la necesidad sonora, Bertran traza ya como labor inicial de la acción militar el canto rítmico fundamental. La forma musical, mesurada, que ha abierto los contornos diáfanos de los muros para cantar góticamente las alabanzas de Dios ${ }^{42}$.

39 No voy a describir aquí en qué consiste justamente esta atmósfera, simplemente remito al ejemplar ensayo, aunque muy discutido, de Hans SEDLMAYR, Die Entstehung der Kathedrale, Zurich, 1950. Nueva edición, Akademische Druck-Graz, 1976. En cualquier caso, véase J.E. RUIz DOMENEC, «El origen de la Catedral: Estética escolástica e ideología eclesiásticas, en Medievalia, I (1980), pp. 49-82.

40 Cfr. J.E. RUIz DOMENEC, La contrautopía arcaica en la sChanson de Roland, VIII Congreso de la Societé Rencesvals, 1978. Para la errancia, y el carácter de la caballería en esta dimensión, véase Erich KOEHLER, op , cit., pp. 79 y ss.

41 Marius SCHNEIDER, El origen musical de los animales-simbolos en la mitología y la escultura antiguas, Barcelona, 1946.

42 H. SEDLMAYR, op. cit., pp. 85 y ss. 
La admisión de un campo sonoro para la acción militar y en concreto para la batalla es una nueva dimensión y un nuevo símbolo de la concupiscencia. Pero en Bertran es asimismo necesidad de comunicación y por consiguiente de búsqueda de un objeto determinado.

* El plano acústico es el plano más adecuado al ser humano. Por eso la reacción natural del hombre a todo cuando observa o le conmueve se traduce por una manifestación acústica. Para dar nombre a las cosas, el hombre tiene que crear ritmos acústicos adecuadamente timbrados y articulados, a saber, palabras; y estas palabras no pueden ser otra cosa sino imitaciones rítmicas, directas o adaptadas, onomatopeyas (imitaciones de fenómenos acústicos) o transposiciones en el plano acústico de impresiones sensoriales no acústicas: ${ }^{43}$. Estas observaciones de Marius Schneider nos colocan delante de la realidad más honda que Bertran trata de exponer como un ritmo sonoro, imposible de reducir a cualquier otra circunstancia estética.

Esto se aprecia sobre todo en la renovación que hace del uso lingüístico. Las afirmaciones y los estremecimientos finales, en los que Bertran traza la nueva fisonomía de la batalla, sirven para aunar las raíces trascendentes, simbólicas, que habían configurado el universo de la epopeya, pero superándolas. De esta manera, abre el camino a una comunicación de colores, de ritmos musicales, de palabras articuladas: es el nuevo sentido de la guerra, de la batalla. Su sonido. Todo es una constante vibración de este instante temporal cuando nace el fuego y brotan como furias los gestos mutilados de la acción militar. Véase cuando dice ${ }^{44}$ :

\section{Quan vei pels vergiers despliear \\ Los cendanz grocs, indis, e blats, M'adoussa la vorz dels chavaus $E^{\prime}$ Ih sonet que fan li joglar, Qwe viulan de trap en tenda. Trombas e corn e graile clar. Adones vuolh un sirventes far}

(Cuando veo desplegar por los vergeles las banderas amarillas, rojas y azules. me alegran los relinchos de los caballos y las melodias que hacen los juglares que van

43 M. SCHNEIDER, op, cit, , p. 29.

44 Ed. C. Appei, op. cit., núm. 22, pp. 55 y ss. Traducción RIQUER, $o p$. cit., pp. $719-719$. 
tocando la vihuela de pabellón en tienda y

trompas cuernos y agudos clarines.

Entonces quiero componer un sirventés).

Como se ve, la ubicación de Bertran es rigurosamente sonora. Casi dionisíaca ${ }^{45}$. Precisamente porque en la naturaleza de la música encuentra la canalización del ruido y la imagen del sacrificio; el objeto en sí que Bertran pretende desarrollar es la exacerbación de lo imaginario y al mismo tiempo la creación de un nuevo orden social y de un sentido revolucionario de integración política ${ }^{46}$. La disolución de la idea antigua del cosmos, que otorgaba al silencio un lugar fundamental en la organización de las «estructuras elementales», otorga ahora al sonido la nueva belleza de tener el sentido de la ordenación y la canalización absoluta. El código que ahora desarrolla la sociedad está simultaneado por todos lados de una presencia invisible, tenebrosa, que es el intento de existir apagando las oscuras conmociones del mundo anterior y su silencio.

De este modo, el sirventés surge de una experiencia estética que se liga a un fenómeno auditivo. Rítmico. Con el cual trata de explicar Bertran la totalidad de sus experiencias sobre el mundo gótico y sobre ese agudo desvarío que les condujo a idear la batalla como rito, como instante extremo, desolador, de las promesas y los destinos de toda la sociedad.

Ateniéndome tan sólo al círculo de los cuatro elementos fundamentales que expone en esta estrofa, ordenaré, de una manera muy

45 Con esta afirmación creo alcanzar el objetivo principal de este trabajo. Ahora puedo ya precisar el tema central del mundo poético trovadoresco, que, aunque siga siendo una modesta contribución al problema central de la sociedad de la segunda mitad del siglo XII, que ando buscando, me permitirá profundizar en su posible desvelamiento. Pero para una investigación de este tipo, el historiador de la sociedad actual debe de ponderar con rigurosidad su propio método y su teoría. Yo creo encontrar en la sobrecargada y ambiciosa tesis de F. NIETZ. SCHE, «Die Geburt der Tragödie aus dem Geiste der Musiks, en Werke, Carl Hanser Verlag, München, I (1976), pp. 17 y 55., un punto de partida legítimo para configurar ese momento de colisión, trágico, que determinó la emergencia de la cultura gótica, de las cenizas de la sociedad feudal. En todo caso, he de señalar que los problemas entre los conceptos del autor y la creación de un enfoque sistemático han sido facilitados por la lectura de dos obras fundamentales, las de E. FINK, Nietzsche Philosopbie, W. Kohlhammer, Stuttgart, 1966, y M. HEIDEGGER, Nietzsche, Pfullingen, Neske, 1961.

46 Precisamente por el hecho de haber inventado una serie de instrumentos sonoros para hacer posible la integración del ritmo auditivo en la estructura de la sociedad. En un sentido teórico, y generalizando los problemas, ha sido señalado por J. ATTAU, op. cit., pp. 55 y ss. 
sumaria todavía ${ }^{47}$, la significación rítmico-sonora que traza el poeta del Peirigord. Los cuatro elementos fundamentales de la gama cromático-sonora están presentes, aunque su orden demande cierta búsqueda porque no es natural, sino cortesano ${ }^{48}$. Bertran asienta todo el proceso de la acción militar en un momento inicial que es verde (pels vergiers), amarillo (grocs), rojo (indis) y azul (blaus) que, según la magistral experiencia de Marius Schneider, correspondería a los sonidos fundamentales: $L a, s o l, f a, s t^{49}$, Naturalmente estos cuatro *sonidos» o elementos fundamentales animan la ruptura del silencio y dan paso a las vibraciones más esenciales donde se establecen los estratos temblorosos de la naturaleza de la acción militar. Justamente el conocimiento de su realidad y de su conjugación rítmica es lo que puede llevarnos más allá de una simple e ingenua observación que vincularía esta presentación cromática, y sonora, a una mera estética del gusto.

Cuando Bertran de Born acentúa el interés que le suscita el mundo cromático y sonoro, no sólo da paso a una comprensión globalizante de un pasado eclesiástico ${ }^{50}$, sino también, y quizás más esencialmente, configura el punto de vista de un planteamiento estético nuevo, el gótico, que, aunque configurado ya en la corte capeta, necesita asegurar sus fundamentos en el mundo aristocrático. De ahí que la coherencia que existe entre la gama cromática y sonora, con los instrumentos que relaciona con ellos, es absoluta: madera, metal, cuerda y de caña (flautas-trompas) que indican la naturaleza estrecha, moral incluso, entre sus ideas rítmicas y la nueva dimensión musical a finales del siglo XII.

El principio creador de la acción sonora de la batalla es una ruptura sensible de la forma creadora original, de la vida vegetativa, del sistema de parentesco, que se vincularía simbólicamente a la

47 Espero profundizar en esta cuestión analizando algunas composiciones poéticas que por su ritmo lingüístico permitan una mayor hondura en el tema, y puedan así proporcionarnos la grandeza de esta convulsión sonora que acompañó a la destrucción de la sociedad feudal. Creo que puede afirmarse que la poesía de los Minnesänger encierra un núcleo creativo excelente en esta dirección, y asimismo estoy convencido de que su estudio puede suministrarnos una guía suficientemente honda para este problema. 1964.

48 Cfr. Jacques CHNineY, Historre musicale du Moyen Age, Paris, P.U.F.,

49 M. SCHNEIDER, op, cit., p. 149.

so Cfr. Barbara H. RosenWEIN, eFeudal war and monastic peace: Cluniac Liturgy as ritual aggressions, en Viator, II (1971), pp. 129-157. 
tierra (como una unidad estrecha entre la aristocracia y la tierra ${ }^{51}$ ), y cuyo sonido fundamental sería la. Es el refugio último del árbol de la vida, asentado en la madera fundamental y en la concavidad máxima de una protección femenina proveniente del carácter matrilateral del matrimonio feudal y no de un psiquismo extravagante. El sentimiento de la quietud en la es la fuerza del sistema de parentesco, el silencio. No hay nada como la realización mundanal en $2 a^{32}$. El cambio sensible que se advierte de inmediato es contemplar la acción como vehículo de destrucción de este principio motor. La acción militar es una destrucción enajenada, se convierte en la verdadera dueña de la nada. Lógica absoluta de la presencia guerrera.

El contacto tierra-aire ( $l a-s o l)$ es la presencia del lugar místico de la figura del dragón, fenómeno necesario para imponer la quête poética sobre la guerra y la batalla (en re) que sería el comienzo absoluto de la acción militar, pero también, naturalmente, de la música contrapuntística de la corte gótica ${ }^{53}$. Con este movimiento esencial se deshace el silencio original al servicio de los príncipes, como en Perotinus y su Sederunt Principes: son los sonidos altos del metal, las trompetas que revelan la nueva orientación de la música gótica. La trascendencia universal del Apocalipsis. Y es así como de nuevo la dimensión de lo imaginario de la Iglesia alcanza absoluta validez, destacando el concepto de agresión y de concupiscencia como el verdadero fenómeno de la conciencia de los feudales a finales del siglo XII.

51 Según se desprende de la inteligente investigación de A. GUVERc, «Représentations et attitudes à l'égard de la propriété pendant le Haut Moyen Agex, en Annales. E.S.C., 1972. Cfr. igualmente su importantísima obra Das Weltbild des mitterlalientichen Menschen, Verlag C.H. Beck, München, 1980.

52 Podria pensarse que voy demasiado lejos; que incluso no podría desprender de una conciencia sonora un universo simbólico, ni siquiera a la inversa. De acuerdo: esto lo sabe hoy casi todo el mundo. Pero no en un periodo de ruptura. Trágico. Creo que Nietzsche logró rebatir algunos prejuicios sobre la exigencia necesaria de un arte que se configura plenamente en una conciencia musical. Rítmica. Sonora. En todo caso las modernas investigaciones sobre las fronteras de la tonalidad y la valoración estética (consecuentemente, también social) de los acordes de seis y más sonidos, nos han devuelto al punto de partida de la música contrapuntística del gótico. Véase Arnold SCHOENBERG. Trasado de armonía, Real Música, Madrid, 1974.

53 El papel del incipiente gótico en la construcción de esa unidad sonora está todavía por estudiar, pero nadie pone en duda hoy que existió una coherente conjunción de intelectuales rodeando la construcción de la gran obra gótica (no en sentido arquitectónico sino estético) Notre Dame de Paris. Cfr. J. BALDWIN, Masters, Princes and Merchants. The social Views of Peter the Cbanter and bis circle, Princeton, 1970. 
Con estos elementos como situación original, Bertran de Born da paso a su verdadera concepción de la acción militar, el sacrificio rojo en $f a$, que es el sonido-símbolo del fulgor, del dolor, de la purificación $n^{54}$. La vida heroica, que es devorada por el fuego inmenso, irrumpe como la vivencia más honda en el mecanismo de la sociedad. El orden del sonido busca la realización distante, dorada, azul: el sonido si. En él culmina la acción sonora de Bertran, permitiendo el desarrollo de un ritmo musical en el intervalo fa-si allamado tritono en la teoría musical antiguas"s". Con él reverencia la nueva dimensión de la batalla, deshaciendo en rojo rumor $(f a)$, el silencio de la tierra (la). El ritmo de tales insinuaciones sonoras está determinado por el valor simbólico del eje principal, fa-si. Como ha escrito Marius Schneider esi el fuego divino ( $f a$, masculino) penetra en la tierra ( $\mathrm{la}$, femenino) sacrificándola para crear en ella un cuerpo terrestre, un alma nueva (nacida espiritualmente en el do y materialmente en $s i$-fa) puede encarnarse en el re ${ }^{56}$. Los golpes, la heridas, son inicio del sacrificio máximo y de la cultura gótica en $r e$. Resonancia casi religiosa, irrupción de un movimiento rítmicosonoro al margen de la naturaleza: imposición, en definitiva, de la idea de la corte y del poder del rey.

De este modo convendrá analizar el interesante, y famoso, sirventés Be'm platz lo gais temps de pascor ${ }^{57}$, debido a que puede considerarse como la descripción más detallada, y perfecta, del nuevo contenido de la acción militar, de la batalla. Este sirventés alimenta la enseñanza de una presencia del universo feudal en tensión, negro, como un rayo negro, disonante, como cl carácter dualista del ritmo musical. Este intervalo disonante denominado tritono en la teoría musical expresa el contacto edoloroso de los elementos agua y fuego y la zona ediscordante de Mitra-Varuna, es decir, la zona de emuertes 58 . Este ha sido finalmente el último arrebato de la teoría trifuncional y del carácter activo de la función del bellator en la Europa occidental ${ }^{59}$.

54 M. SCHNEIDER, $o p$, cit., p. 150.

55 Idem, ibidem, p. 149.

56 Idem, ibídem, p. 154.

57 Ed. C. APPEL, op. cit., núm. 40, pp. 92-94. El autor los coloca entre los dudosos. No obstante, como piensa RIQUER, $O p$. cit. . II, p. 740, esi no fuera obra de Bertran de Born, es evidente que en esta composición se advierte su espíritu y su influjo*, La traducción castellana en este caso también es de Riquer, cit. pp. 740-742.

58 M. SCHNEIDER, op. cit., p. 158.

59 Cfr. G. DuBY, Les trois ordres ou l'imaginaire du feodalisme, cit. p. 202. 
Pero además en este sirventés Bertran de Born piensa la batalla como si fuese la raíz de la existencia. Y en esa estructura introduce el instante de verdad que permite al caballero ser lo que es: quime$\mathrm{ra}$, constelación de un mundo imaginario que da razón de su victoria en el acto más sublime de la acción militar en las últimas décadas del siglo XII. Es la realidad que bruscamente se impuso en las fronteras finales del mundo feudal: la realidad de Alarcos, de $\mathrm{Mu}$ ret, de Bouvines. Es decir, la simple constatación de un universo sonoro, rítmico, cortesano, donde moran las rutilantes luces de una acción que enaltece a los mejores, y que pone de manifiesto la ruina de los sistemas normativos feudales. Ruina a la que la propia poesía de Bertran le ha ofrecido su legitimación. Pero ahora hace posible un llanto poético que le confiere a la caballería la capacidad de aprehenderse y modelarse a partir de sufrimientos y de delirios sin nombre. Ser caballero significa, desde 1180 en adelante, tener una forma sacramental que oculta una creciente sombra sobre su existencia. Los últimos feudales, indómitos, se abren sobre el mundo según la polaridad de individuación y participación que permite la formación de unas estructuras modélicas, imaginarias, que definen un nuevo sentido de la existencia, del valor y de la virtud. La forma que hace de un caballero-lo-que-es es rigurosamente ese determinado poder-de-ser en los sistemas de valores caballerescos. La forma de la caballería es lo que hace ser al caballero, caballero; lo que le da el carácter general de la caballerosidad.

Así, la batalla llega a constituir un problema en la actividad cultural de la clase dirigente en las últimas décadas del siglo XII. En la batalla, y no en la guerra, los materiales dados, la cosas o los acontecimientos que tienen una forma natural, son transformados por las funciones racionales, imaginarias del acto creativo, cortesano, que se asienta en un sonido inicial: gótico.

El paisaje posee una realidad histórica que al mismo tiempo le da coherencia al contenido. Bertran utiliza la forma natural de un paisaje como material para una creación artística cuyo contenido ya no es aquel material, sino más bien lo que él ha hecho a partir de él, la circunstancia creadora del sonido de la batalla.

Este sirventés es la expresión de una sustancia abierta, desgarrada, que intenta elevarse alumbrando la acción más nuclear que posibilita a la caballería manifestarse como lo que es: la ideología de la clase dominante. En efecto, el ideal caballeresco es la sombra pálida que permite comprender cómo, a partir de 1180 , la acción militar es puramente el reverso de lo que significó en la época anterior. En 
la batalla se oyen sonidos que envuelven la circunstancia misma de una razón vital, dinámica, subjetiva, sacramental. Esta interiorización ritual sirvió para el despliegue de los valores más cruciales de la caballería: la lealtad, el coraje, el amor ${ }^{60}$.

Así se consolidan las pasiones más hondas de un universo nuevo que se abre lentamente al mundo. Un estilo revolucionario en la descripción de lo que significa la batalla, permite a Bertran desglosar todo el sentido moral que exige para su clase. Es asimismo el poder expresivo que este sirventés lleva en su seno, y su pertenencia a un estilo particular de poesia trovadoresca que exalta no sólo los valores militares, sino también la agitación convulsiva de la agresión concupiscente:

\author{
Be'm plarz lo gais temps de pascor \\ que fai fulhas e flors venir: \\ e platz mi, quan auch la baudor \\ dels anzels, que fan retenir \\ lor chan per lo boschatge; \\ e platz mi, qan vei sobre'ls pratz \\ tendas $e$ pavilhos fermaz;
}

(Me gusta el alegre tiempo de primavera que hace nacer hoja y flores, me gusta oir el júbilo de los pájaros que hacen resonar su canto por el seto y me gusta ver plantados en el prado tiendas y pabellones).

En estos versos se observa con facilidad la presencia del elemento de la polaridad entre la forma natural y la dinámica militar. En los tres elementos fundamentales que configuran el gusto del pocta: lo gais temps de pascor, la baudor dels auzels, y sobre'ls pratz tendas e pavilhos está presente la exigencia de conformar un algo social, cultural y político. ¿Qué es ese algo? Antes le he llamado concupiscencia, por eso dice más adelante:

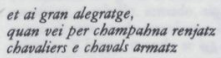

(y tengo gran alegría cuando veo alineados por el campo caballeros y caballos armados).

60 Georges DubY, Saint Bernard. L'Art Cistercien, Paris, 1976, p. 176. 
La alegría ritual, sacramentaria, concupiscente, por ese instante inicial, por esa situación de umbral ante el acto mismo de la batalla. La alegría del sacrificio como inicio absoluto de un momento ritual omniinclusivo, que fortalece la imagen de la clase dominante en su función más honda, nuclear: su función militar. De ahí que no pueda pensarse la dinámica de la guerra como algo que pueda surgir abiertamente del ritmo natural, objetivo; por el contrario, la batalla debe verse como el símbolo de la ruptura con el ritmo natural, con el orden que él ha impuesto durante décadas en el suelo europeo. Es, pues, una realidad imaginaria, subjetiva, quien legitima ahora la acción guerrera y la agresión. Más aún, el no-ser de la naturaleza se entiende como un sacramento de renovación religiosa: he aquí la razón profunda del dinamismo cultural social y político que tiene la batalla en las últimas décadas del siglo XII.

En efecto, la batalla se convierte en el elemento potencial, supremo, que ordena subjetivamente un saber al margen de la naturaleza. Ella despliega, descendiendo sobre el ser de la naturaleza, un sonido errante que es auténtico no-ser. El contraste supremo se establecerá entre el universo cuya forma es nigromante, cerrada, central, y el sacramento ritual que tiene una forma diáfana, lúcida, transparente.

Pero hay más. El contraste entre el mundo natural y la dinámica de la acción militar (es decir, por un lado el ritmo cósmico del tiempo primaveral y la resonancia de los pájaros, y, por otro, la presencia de un elemento externo, disturbador, en las tiendas que prefiguran la batalla) es el principio litúrgico por excelencia ${ }^{61}$. En él subyace además la ordenación social para evitar que el dinamismo de la acción militar lleve al caos, es decir, a esa noche del vacío que precede siempre a un acto de renovación litúrgico.

En ese sentido, para Bertran de Born toda la acción convulsiva será completada por el resultado mismo de la batalla, que naturalmente tambiên le place:

\footnotetext{
E platz mi, quan li corredor fan las gens a liaver fugir; e platz mi, quan vei apres lor gran re d'armatz ensems venir; e platz m'en mon coratge, quan vei fortz chastels assetjatz
}

61 Ídem, Le dimanche de Bouvines, cit., p. 149. 
e vei l'ost el ribatge

qu'est tot entomo claus de fossatz

ab lissas de fortz pals serratz.

(Y me gusta que los exploradores hagan huir a la gente con su hacienda, y me gusta cuando veo venir detrás de ellos gran número de armados en grupo, y le place a mi corazôn ver sitiados fuertes castillos y los muros rotos y arruinados, y ver la hueste en la orilla completamente circundada de fosos con empalizadas de fuertes $y$ apretadas estacas).

Aquí se puede ver en su significación literal la función psicológica, social, política y cultural de la batalla. Inagotable presencia de un acto de regeneración absoluta que estremecidamente hace surgir a la clase dominante como caballería.

Ahora bien, toda teoría sobre la guerra que suprima el elemento dinámico de la estructura de parentesco, por la energía de la corte ha de explicar la aparición de ese proceso vital y de hablar de un modo estricto del comienzo de ese acto cultural que aún sigue siendo la vida misma. La polaridad de la dinámica y la forma aparece en la experiencia inmediata del noble como la estructura polar de la vitalidad y de la intencionalidad de todos sus actos. Así dice Bertran:

\author{
E autresi'm plarz de senbor, \\ quan es primiers el'envaizir \\ en chaval, armatz, ses temor, \\ qu'aissi fai los sieus enardir \\ $a b$ valen varsalatge \\ E puois que l'estorn es mesclatx, \\ chascus deu esser acesmatz \\ e segre'l d'agnadatge, \\ que nuls om non es re prezatz, \\ tro qu'a maintz colps pres e donatz \\ (Y también me gusta el señor cuando es el primero \\ en atacar, a caballo, armado, sin miedo, \\ y que de este modo enardece a los suyos con gallarda \\ bravura. Y luego, cuando se ha iniciado la refriega, \\ todos deben lestar prestos para seguirlo de buen \\ grado, pues ningún hombre es apreciado en nada \\ hasta que ha dado y ha recibido muchos golpes).
}

Detengámonos aquí un instante. La presencia de los valores vitales e intencionales de la batalla están presentes en dos conjuntos 
que en su concurrencia se complementan: en chaval, armatz y ses temor. Ambos conjuntos necesitan justificación y explicación. La acción militar a partir de 1160 se ha convertido en un poder que exige del guerrero a caballo, del caballero, el choque. Este es el impulso vital de la sustancia de un hacer técnico, cultural y social, creador de nuevas formas y de nuevos contenidos de la acción militar. El choque aparece aquí como el elemento más vital del hombre, dinámico: el significado de esta acción, expresada en el conjunto en chaval, armatz está coloreado por su contraste polar, concurrente y completivo, en el pleno sentido de la palabra, la conciencia que quiere imponer Bertran, ses temor es la necesidad de que el caballero no esté sujeto a ninguna estructura limitadora a priori de orden subjetivo. De ahí que el correlato indesligable de esta transformación es el desarrollo del coraje ccette nouveauté du XII siècles ${ }^{62}$.

Efectivamente, este cambio en la moral y en el sentido de la agresión crea los nuevos contenidos técnicos y religiosos de la acción militar. La relación entre el elemento dinámico, el choque, y el elemento subjetivo de la vida, el temor, buscará traspasar los límites de la necesidad natural en las infinitas variaciones que se producen en su seno a lo largo del siglo XIII, debido a las nuevas formas creadas por el proceso evolutivo de la técnica del armamento, del sentido social de la guerra y del carácter de la agresión ${ }^{63}$. Esta relación entre la vitalidad del nuevo acto primordial de la guerra y el temor es la única que en el pleno sentido de la palabra nos ilustra sobre la dimensión de la transparencia en imágenes de cielos y de colores, rechinantes, que manchan imaginariamente las palabras muertas, los árboles de metales incandescentes o, más aún, ese desierto inmaterial que Betran graba en un horror que deshace los fundamentos de la autoconservación del individuo en la sociedad feudal. Y así exclama desde lo hondo de su ser como noble, musitando la destrucción enajenada de su mundo y la necesidad del abismo grave de seguir siendo feudal:

\section{Massas e brans, elms de color, escutz trauchar e desguamir}

62 fdem, ibidem, p. 27.

63 Véase, por ejemplo, el temor que inunda las múltiples miniaturas de es. cenas guerreras que poseemos del siglo XIII; especialmente significativa en este sentido es la soberbia iconografia de la Chanson de Aspremont (conservada en el British Museum). Cfr. los folios 31 recto y verso donde los guerreros, caballeros, huyen con una faz distorsionada por el terror a las armas arrojadizas: ballestas. 
veirem a l'entrar de l'estor

e maintz vassals ensems ferir,

don anaran arratge

chaval dels mortz e dels nafratz

E quan er en l'estom entratz

chascun om de paratge

no pens mas d'asclar chaps e bratz

(Veremos al principio de la lucha tomperse y

descomponerse mazas y espadas, yelmos de colores

y escudos, y a muchos vasallos hiriendo al mismo

tiempo por lo que los caballos de los muerros

y de los heridos vagarán errabundos. Todo hidalgo,

una vez entrado en la refriega, sólo debe pensar

en cercenar cabezas y brazos).

Esta estrofa muestra con claridad los sueños, las imágenes, las oscuras aguas de los pozos a los que la agresión había conducido a la sociedad feudal. Pero nuestro poeta, al reconocer esta situaciôn, es consciente de su propia situacionalidad contradictoria e imposible. Una vitalidad dirigida en un sentido destructivo termina por destruirse a sí misma y esto ocurre porque la batalla se asienta sobre un tipo de agresión que no posee una base de infinita profundidad, como había tenido en décadas anteriores al asentarse en las normas del sistema de parentesco. El mejor ejemplo de ello lo constituye ese gemido triste que determina todo el pensamiento, el más profundo y completo que Bertran de Born logró llevar a cabo. Es lo que en último término inspiró todo el contenido poético de su obra. La autotrascendencia la experimenta de un modo inmediato sobre el propio roce acantilado de un pensamiento mudo, sobre el abismo vital. Y así como desde el punto de vista del parentesco, Bertran se había encontrado imperfecto y se halló frente a una esfera de propiedad negativa, ahora recubre de sangrientas violetas sin limitación alguna y en todas las direcciones, bajo la claridad de los relámpagos, el verso más agudo, el más terrible que se ha escrito sobre la dimensión de la acción militar en la época feudal:

que mais val mort que vius sobratz

(pues vale más morir que sobrevivir vencido)

Esto significa, estrictamente hablando, que sólo quien tiene la posibilidad de realizarse en la acción militar tiene un sino. Y tener esa alternatíva significará aún, espontáneamente en la sociedad feu- 
dal, ser libre. Puesto que la libertad y el destino constituyen una polaridad en la que solamente la guerra participa en su naturaleza radical. Más aún, la batalla se aplica en esa situación que se da entre la estructura ontológica fundamental y el resto de polaridades ontológicas. Todo lo que es fuego se ha convertido en dolor y en humedad morada:

e veis chazer per los fossatz pauss e grans per l'erbatge

(y veo caer a grandes y pequeños por los fosos en el herbaje).

Como se ve con facilidad, son palabras azules que advierten los límites que no logra franquear la sociedad, y sobre los que Bertran no creerá oportuno ofrecer un diagnóstico. Bertran de Born no, pero Wolfram von Eschenbach, sí. Su poesía no trasciende, como la de Wolfram, la finitud de la vida real, para instalarse en otro espacio, en otro tiempo. Tal circunstancia transforma el contenido de su verso que ahora vuelve a ser puramente musical: es un intervalo que describe, en un tritono básico, el modo y el significado de la batalla. De sus votos. De sus promesas.

La estructura de esta finitud está descrita en su poesía en la forma peculiar que tiene de presentar esos extraños acordes de la situación negra, petrificada, de la última imagen de la batalla feudal:

e vei los mortz que pels costatz

an los tronzos ab los cendatz

(y veo los muertos con los flancos atravesados

por astillas con los cendales)

Me voy a permitir concluir aquí. Como hemos visto, hacia el año 1190 se han roto los sistemas normativos feudales, y del pozo de esta ruptura ha surgido un nuevo concepto del acto guerrero: cayendo los símbolos interdependientes de la acción militar. En tal situación Bertran de Born, poeta y trovador, entabla una lucha profunda para salvaguardar el principio creador de la acción militar, es decir, la expectación de la batalla, como rito cósmico de organización eclesiástica. He aquí donde la Iglesia adoptó la decisión y salvó el carácter histórico de la clase dominante feudal, al convertir los 
principios aristocráticos en normas nobiliarias ${ }^{64}$. Al filo del 1200 todo el universo laico se inscribe en la aguda coherencia que existe entre una nobleza como clase de orden y una caballería como sistema de valores en ascenso. Esto es lo que se observa cuando se analiza la circunstancia histórica que condujo entre 1190-1195 a Bertran de Born a dar una significación universal al sentido de la guerra, más aún, al sentido de la batalla, configurando para siempre la validez de una estética sonora contada como si fuese ráfagas de fuego: condicionada de un movimiento histórico contingente que llevó a los hombres a realizarse íntegramente en el mismo sonido de la batalla. En ella se oyen gemidos que ocultan el espantoso silencio, exasperado, de un destino donde todo fue inútil.

Este fue en último término el absorto universo de Bertran de Born, triste, grave, que encierra una voz que musita alaridos de muerte, pero también de vida y de tesurrección. A light is sew'en for the pious. / A light is sew'en for the repenting sinner.

64 Para esta aguda transformación, provocada además por la corte y sus ideólogos fundamentales, me permito remitir a J.E. RUIz DOMÉNEC, El juego del amor como re-presentación del mundo en Andrés el Capellán, Bellaterra, 1980. 